\title{
Recognition of Short-Time Specific Random Elements in Random Sequences
}

\author{
Laimutis TELKSNYS, Jonas KAUKĖNAS \\ Recognition Processes Department, Vilnius University Institute of Mathematics and Informatics \\ Goštauto 12, LT-01108 Vilnius, Lithuania \\ e-mail: laimutis.telksnys@mii.vu.lt, jonas.kaukenas@mii.vu.lt
}

Received: June 2010; accepted: January 2011

\begin{abstract}
In this paper we consider random sequences in the background of which specific shorttime random elements can emerge. The theory and constructive methods for recognition of shorttime specific random elements that may emerge in the background of random sequences are expounded. The results of experimental investigations are presented. The prospects for a wider application of the results obtained are discussed as well.
\end{abstract}

Keywords: recognition, random sequences, short-time random events, stochastic dynamic systems.

\section{Introduction}

The operation of dynamic systems is accompanied by random phenomena of a varying nature that reflect their functioning peculiarities. By analyzing the signals that describe the properties of these stochastic phenomena, one can recognize the states of dynamic systems (Atanasov et al., 2010; Pupeikis, 2010). We can find out whether the operation mode is normal or of pre-emergency state, dangerous and trustful. We can also measure the time instants when the properties of dynamic systems are changing (Willsky, 1976; Shaban, 1980; Kassam, 1980; Kligiené et al., 1983; Basseville et al., 1985, 1993; Telksnys, 1986, 1987). Here we face another set of problems, when short-time specific random events emerge at random time moments, while dynamic system is operating. Then, in the background of a random signal that characterizes normal operation of the dynamic system, we have to recognize the short-time random signals appearing at random time moments. Problems of this nature arise, for instance, when solving the cardiovascular system's functional condition evaluation problems (Klersy et al., 2009; Goss et al., 2009). With an intention to solve the problems of this kind, we further present the recognition theory and a constructive method of short-time specific random signals that appear at random time moments in the background of a random signal.

\section{Statement of the Problem}

Let us consider a random sequence

$$
Y(i)=X(i)+S(i), \quad i=1, \ldots
$$


The component $X(i), i=1, \ldots$ in it is a random sequence described by the Gauss law with the mean $M=E X(i), i=1, \ldots$, standard deviation $D=[E(X(i)-$ $\left.M)^{2}\right]^{1 / 2}, i=1, \ldots$ and covariance function $K(j)=E\{[X(i)-M][X(i+j)-M]\}$, $i=1, \ldots, j=1, \ldots, J . M, D, K(j), j=1, \ldots, J$ - are unknown characteristics.

The second component is represented by an expression

$$
S(i)= \begin{cases}C(i), & i=i 1, i 2, \ldots, i L \\ 0, & i \neq i 1, i 2, \ldots, i L\end{cases}
$$

where $C(i), i=i 1, i 2, \ldots, i L$ short time specific random elements are elements of a single sequence of random amplitude that emerge of random time moments.

We observe the sample

$$
y(i)=x(i)+s(i), \quad i=1, \ldots, N
$$

of a random sequence $Y(i)=X(i)+S(i), i=1, \ldots$.

In (3) $x(i), i=1, \ldots, N$ is a sample of the random sequence $X(i), i=1, \ldots$ and

$$
s(i)= \begin{cases}c(i), & i=i 1, i 2, \ldots, i L \\ 0, & i \neq i 1, i 2, \ldots, i L\end{cases}
$$

are a sample of the random sequence $S(i)$.

We need to determine the argument values $i=i 1, i 2, \ldots, i L$ of appearance of the short-time random specific elements $y(i)=x(i)+s(i), s(i) \neq 0, i=i 1$, $i 2, \ldots, i L$.

\section{Solving of the Problem}

First, we analyze situation when

$$
\begin{aligned}
& Y(i)=X(i)+S(i), \quad i=1, \ldots, \\
& S(i)= \begin{cases}C(i), & i=i 1 \\
0, & i \neq i 1 .\end{cases}
\end{aligned}
$$

Define a sequence of random variables

$$
U(i)=[X(i)-M] / D, \quad i=1,2, \ldots,
$$

$M$ and $D$ are unknown.

Instead of $M$ and $D$ we use their estimates $m$ and $d$ :

$$
m=\frac{1}{N} \sum_{i=1}^{N} x(i)
$$




$$
d=\left\{\frac{1}{N-1} \sum_{i=1}^{N}[x(i)-m]^{2}\right\}^{1 / 2}
$$

Afterwards, we describe the sample $u(i)$ of the random $U(i)$ by a random sequence

$$
u(i)=[x(i)-m] / d, \quad i=1, \ldots, N
$$

That is distributed by Tompson's law with $N-2$ degrees of freedom (Kruopis, 1977):

$$
f(N, t)= \begin{cases}\frac{1}{\sqrt{\pi(N-1)}} \frac{\Gamma\left(\frac{N-1}{2}\right)}{\Gamma\left(\frac{N-2}{2}\right)}\left(1-\frac{t^{2}}{N-1}\right)^{\frac{N-4}{2}}, & || t|<\sqrt{N-1}| \\ 0, & || t|>\sqrt{N-1}|\end{cases}
$$

We shall look for the short-time random specific elements $y(i)=x(i)+c(i)$ in the following manner.

Suppose that there are no components $c(i)$ in the sample $y(i), i=1, \ldots, N$, i.e., $c(i)=0$. Then $y(i)=x(i), i=1, \ldots, N$.

We find the $u(i), i=1, \ldots, N$ element

$$
u(k)=\max _{1 \leqslant i \leqslant N}|u(i)|
$$

Let us consider the event $A: u(i) \geqslant u(k)$. A probability for appearance of event $A$ (Kruopis, 1977) is:

$$
p=\operatorname{Prob}[U(i) \geqslant u(k)]=\int_{u(k)}^{\infty} f(N-2, t) d t .
$$

By using Bernulli's scheme, we observe the events $A: u(i) \geqslant u(k), i=1, \ldots, N$. We calculate count the amount quantity $n$ of events $A: u(i) \geqslant u(k), i=1, \ldots, N$. $n$ of events is distributed by the binomial law (Kruopis, 1977)

$$
B(N, p, n)=C_{N}^{n} p^{n}(1-p)^{N-n}
$$

As $n=1$, the estimate of the probability of event $A: u(i) \geqslant u(k), i=1, \ldots, N$ is $p(A)=\frac{1}{N}$.

We check hypothesis $H$ that $p(A)<p$ with the reliability level $\alpha$.

If the data contradict hypothesis $H$, then we can state with the probability $\alpha$ that $y(k)=x(k)+c(k)$ is a short-time random specific element. In this case, the procedure of search for short-time random specific elements is over.

If the data do not contradict hypothesis $H$, then the assumption that there are no shorttime random specific elements in the observed sequence $y(i), i=1, \ldots, N$ is true with the probability $\alpha$. It means that there are no short-time random specific elements. 
In spite of that, we can proceed with the search of short-time random specific elements by involving more information, making use of differences $y(i)-y(i+r), r=1, \ldots, R$ of the sequence $y(i)$.

Let us define a sequence of random variables

$$
U r(i)=[(X(i)-X(i+r))-M r] / D r, \quad i=1,2, \ldots,
$$

where $M r=E[X(i)-X(i+r)]$ is the mean of the sequence $X(i)-X(i+r), i=1, \ldots$ and $D r=\left[E((X(i)-X(i+r))-M r)^{2}\right]^{1 / 2}$ is a standard deviation of the sequence $X(i)-X(i+r), i=1, \ldots$.

$M r$ and $D r$ are unknown. We shall use estimates $m r$ and $d r$ instead of $M r$ and $D r$ :

$$
\begin{aligned}
& m r=\frac{1}{N-r} \sum_{i=1}^{N-r}(x(i)-x(i+r)), \\
& d r=\left\{\frac{1}{N-r-1} \sum_{i=1}^{N-r}[(x(i)-x(i+r))-m r]^{2}\right\}^{1 / 2} .
\end{aligned}
$$

Thus, the realizations $u r(i)$ of the random sequence $U r(i)$ are described by a random sequence

$$
u r(i)=\{[x(i)-x(i+r)]-m r]\} / d r
$$

That is distributed by the Thompson's law (Kuopis, 1977) with $N-r-2$ degrees of freedom.

We make an assumption that there are no components $c(i)$ in the sample $y(i)$, $i=1, \ldots, N$, i.e., $c(i)=0$. Then $y(i)=x(i), i=1, \ldots, N$.

We find an element of $u r(i), i=1, \ldots, N-r$ :

$$
u r(k)=\max _{1 \leqslant i \leqslant N-r}|u r(i)|
$$

Let us deal with the event $A r: u r(i) \geqslant u r(k)$. A probability for appearance of the event $\operatorname{Ar}$ (Kruopis, 1977) is:

$$
p r=\operatorname{Prob}[u r(i) \geqslant u r(k)]=\int_{u r(k)}^{\infty} f(N-r-2, t) d t .
$$

Making use of the Bernulli scheme we observe the events $\operatorname{Ar}: \operatorname{ur}(i) \geqslant u r(k)$, $i=1, \ldots, N-r$. We count the quantity $n$ of events $\operatorname{Ar}: \operatorname{ur}(i) \geqslant u r(k), i=$ $1, \ldots, N-r$. The quantity $n$ of events is distributed by the binomial law (Kruopis, 1977):

$$
B(N-r, p r, n r)=C_{N-r}^{n r} p^{n r}(1-p r)^{N-r-n r} .
$$


It the event appears once as $n r=1$, the estimate of probability of the event $A r$ is $\operatorname{pr}(A r)=\frac{1}{N-r}$.

We check up hypothesis $H r$ that $p(A r)<p r$ with the reliability level $\alpha$.

If the data do not contradict the hypothesis $\mathrm{Hr}$, then the assumption that there are no short-time random specific elements in the observed sequence $y(i), i=1, \ldots, N$ is true with the probability $\alpha$. It means that there are no short-time random specific elements in the sequence $y(i), i=1, \ldots, N$ observed. Therefore we continue the search procedure.

If the data contradict hypothesis $\mathrm{Hr}$, then we can affirm with the probability $\alpha$ that $y(k)=x(k)+c(k) \vee y(k+r)=x(k+r)+c(k+r), r=1, \ldots, R$ is a shorttime random specific element. In this situation, we terminate the procedure for searching short-time random specific elements.

\section{Experimental Investigation}

For experimental investigation of the recognition theory created for detecting recognizing short-time specific random elements in random sequences, a software has been developed, which covers $3 \mathrm{MB}$ of computer memory.

We shall of illustrate the results of experimental tests research in search of shorttime random specific elements by modelled and real examples of random sequences in recognizing short-time heart rhythm disorders. In all the figures, the vertical segments in their upper part represent values of the sequences $y(i), i=1, \ldots, N$. In their lower part, the some sequences $y(i), i=1, \ldots, N$ are illustrated, where the elements of the sequence marked in black dark are identifiable recognized as short-time random specific elements.
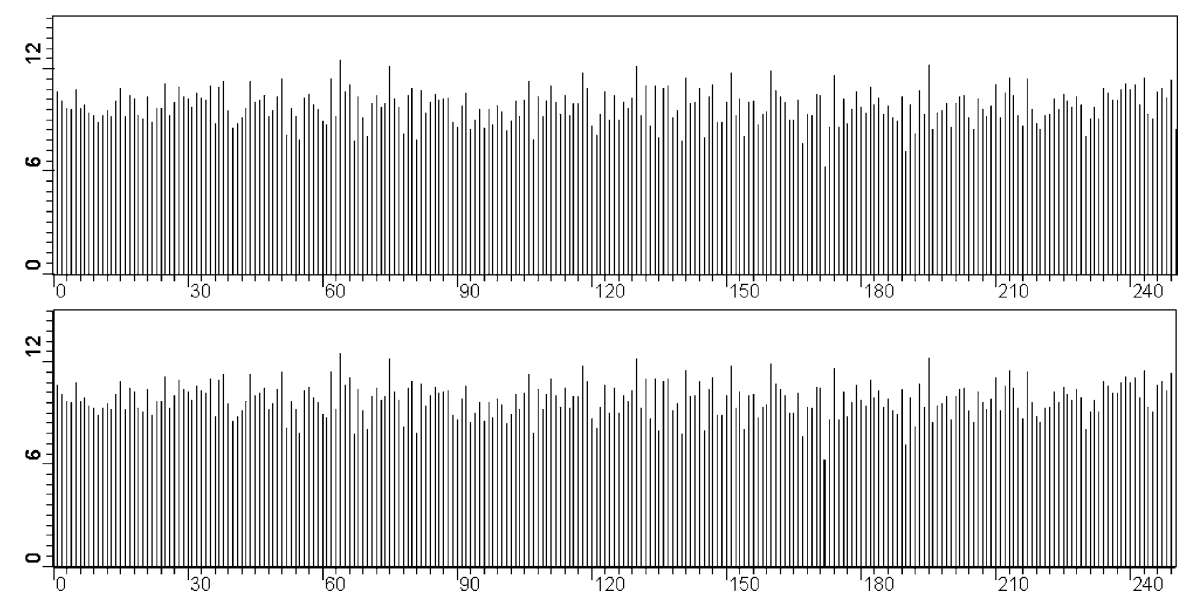

Fig. 1. The upper picture represents the sequence $y(i)=x(i)+10+c(i), x(i)=V(i), V(i)-$ Gauss non-correlated random sequence with $E V(i)=0, E V^{2}(i)=1, i=1, \ldots, 250, c(172)=-3.4027$ is illustrated in which there is one short-time random specific element $y(172)$. The lower picture shows that the short-time random specific element $y(172)$ was found correctly. 


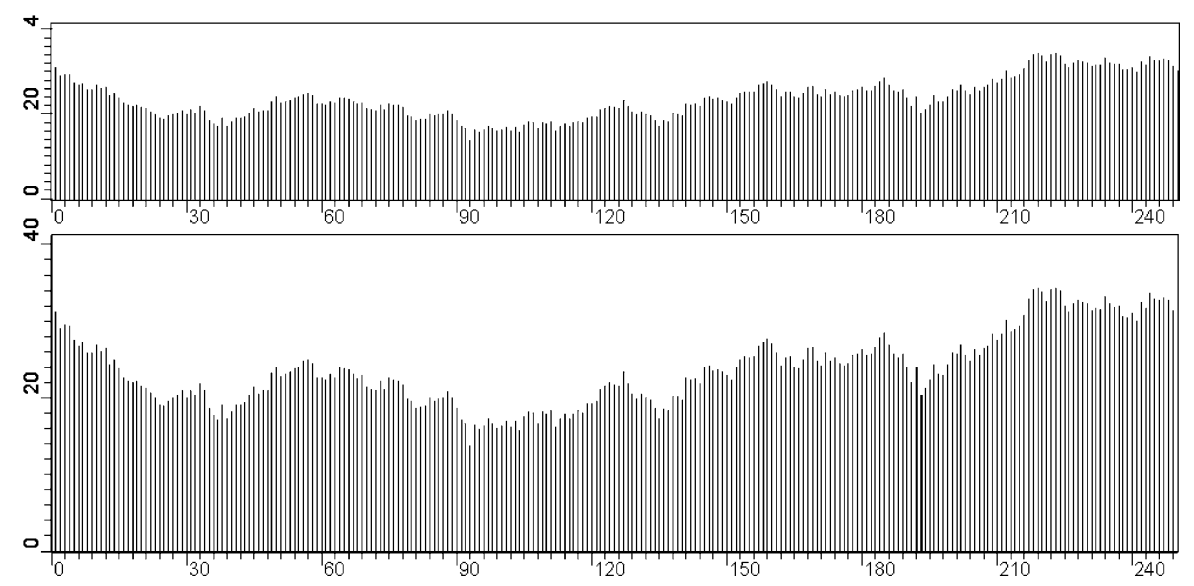

Fig. 2. The upper picture represents the sequence $y(i)=x(i)+25+c(i), x(i)-25=0.99[x(i-1)-25]+$ $V(i), V(i)$ - Gauss non-correlated random sequence with $E V(i)=0, E V^{2}(i)=1, i=1, \ldots, 250$, $c(192)=2.4657$ in which there is one short-time random specific element $y(192)$. The lower picture shows short-time specific random elements $y(192) \vee y(193)$, because the decision was made using the difference $y(i)-y(i+1), i=1, \ldots, 249$ of the sequence $y(i)$.
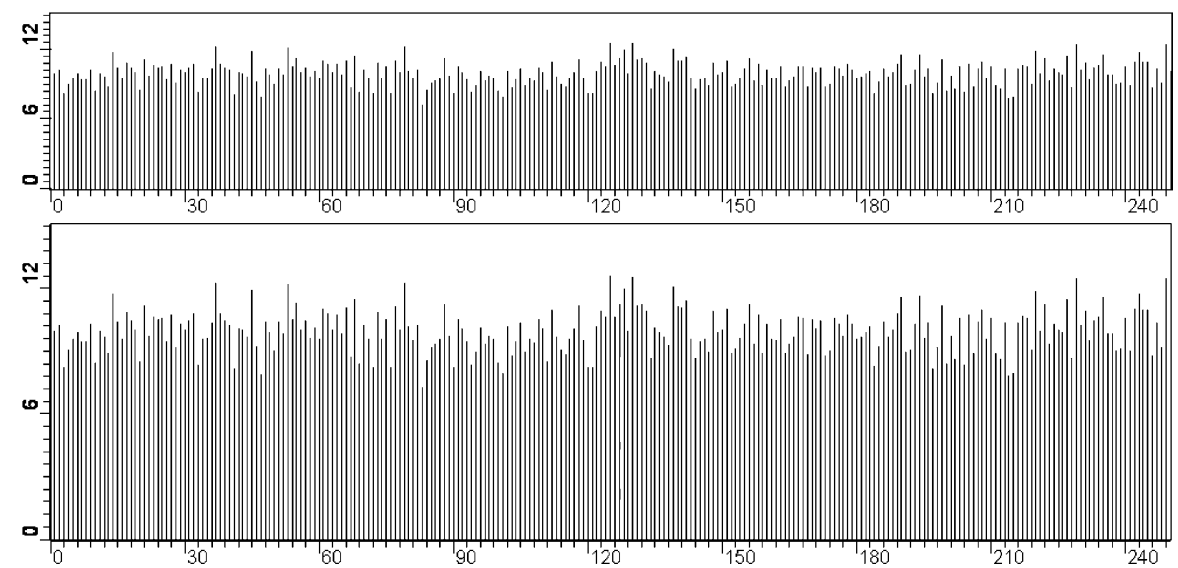

Fig. 3. The upper picture represents the sequence $y(i)=x(i)+10+c(i), x(i)=V(i), V(i)-$ Gauss non-correlated random sequence with $E V(i)=0, E V^{2}(i)=1, i=1, \ldots, 250, c(83)=-1.9872$. is a short-time random specific element $y(83)$. The lower figure shows that a short-time random specific elements was not-found.

The modelled results when $\alpha=95 \%$ are presented in random sequences in which there are:

- are short-time random specific elements and they are found (Figs. 1 and 2);

- are short-time random specific elements, but they are not found (Fig. 3);

- are no short-time random specific elements, but they are found (Fig. 4);

- are no short-time random specific elements and they are not found (Fig. 5). 
We give two examples that illustrate the usage of the method for actual solution of problems. We observe action of the heart of a freely moving person, using the computer equipment in wear. We register time intervals between adjacent systoles and obtain a random sequence $y(i), i=1, \ldots, N$ called a rhytmogram. Making use of the given method, in the rhythmogram we shale look for short-time random specific elements that emerge due to heart rhythm (Fig. 7) or conduction disturbances (Fig. 6).
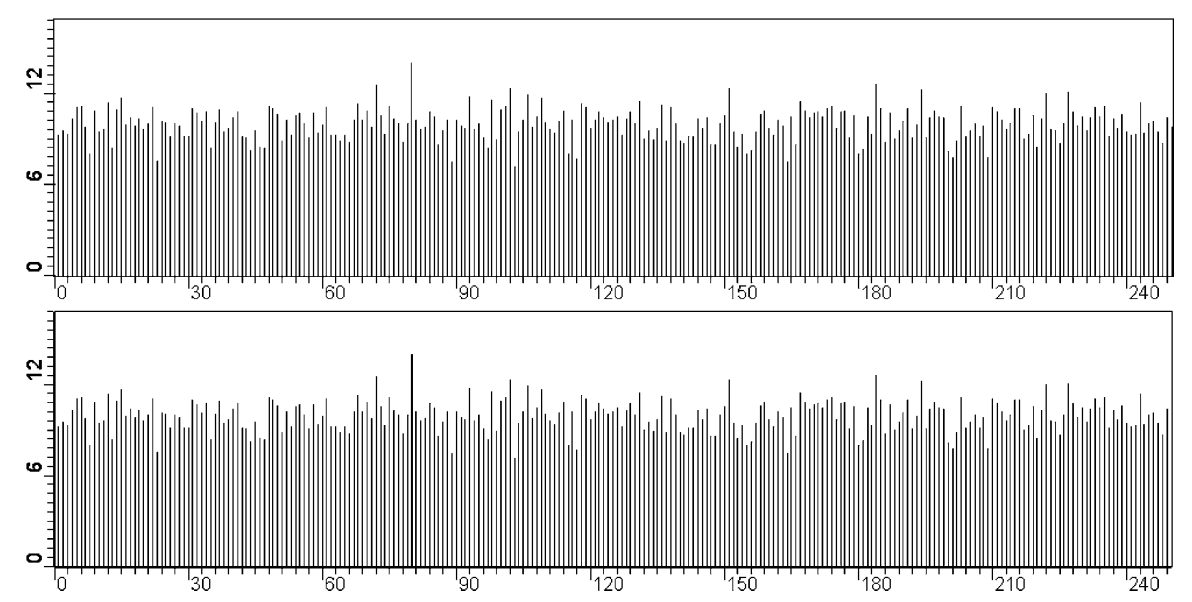

Fig. 4. The upper picture represents the sequence $y(i)=x(i)+10, x(i)=V(i), V(i)$-Gauss non-correlated random sequence with $E V(i)=0, E V^{2}(i)=1, i=1, \ldots, 250$ in which there are no short-time random specific elements. In the lower picture, an element of the sequence is marked in black dark which was faulty recognized as a short-time random specific element.

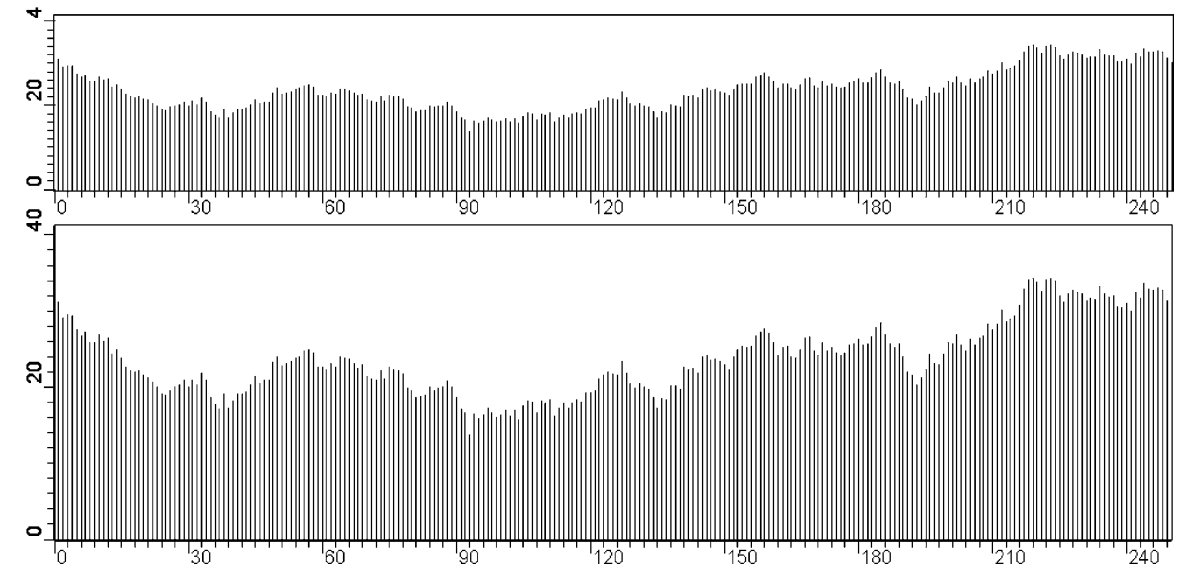

Fig. 5. The upper picture represents the sequence $y(i)=x(i)+25, x(i)-25=0.99[x(i-1)-25]+V(i)$, $V(i)$ - Gauss non-correlated random sequence with $E V(i)=0, E V^{2}(i)=1$, in which there are no short-time random specific elements. The lower picture shows that the recognition system has made correct decisions: short-time random specific elements are not found. 

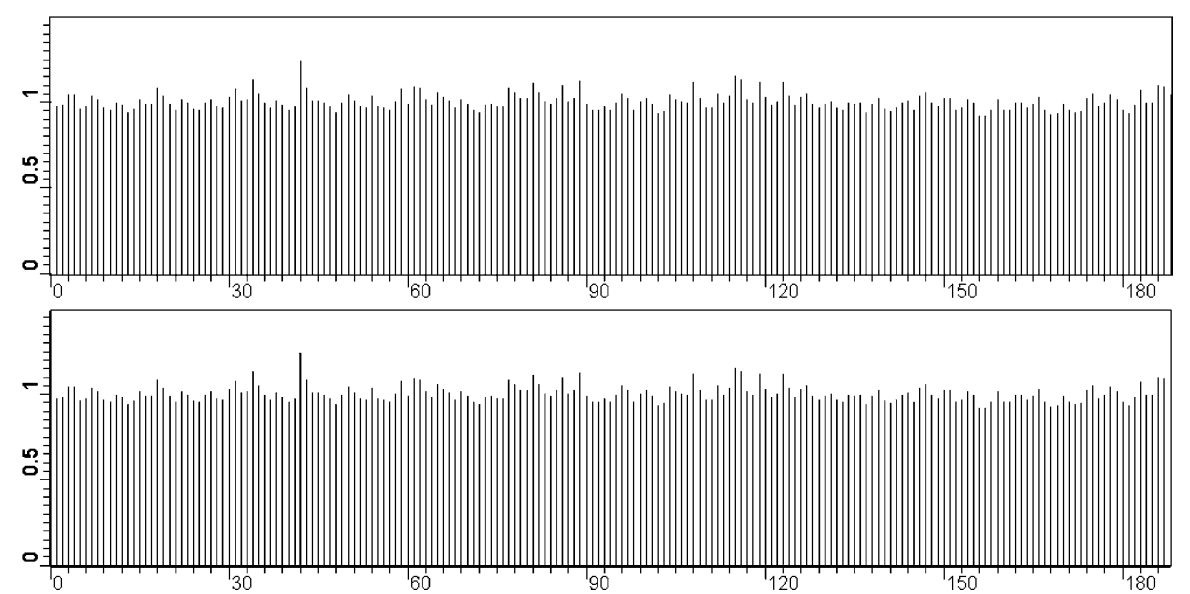

Fig. 6 . The upper picture represents the sequence $y(i), i=1, \ldots, 188$ in which there is a conduction trouble. The lower picture shows that the recognition system has made a correct decision.
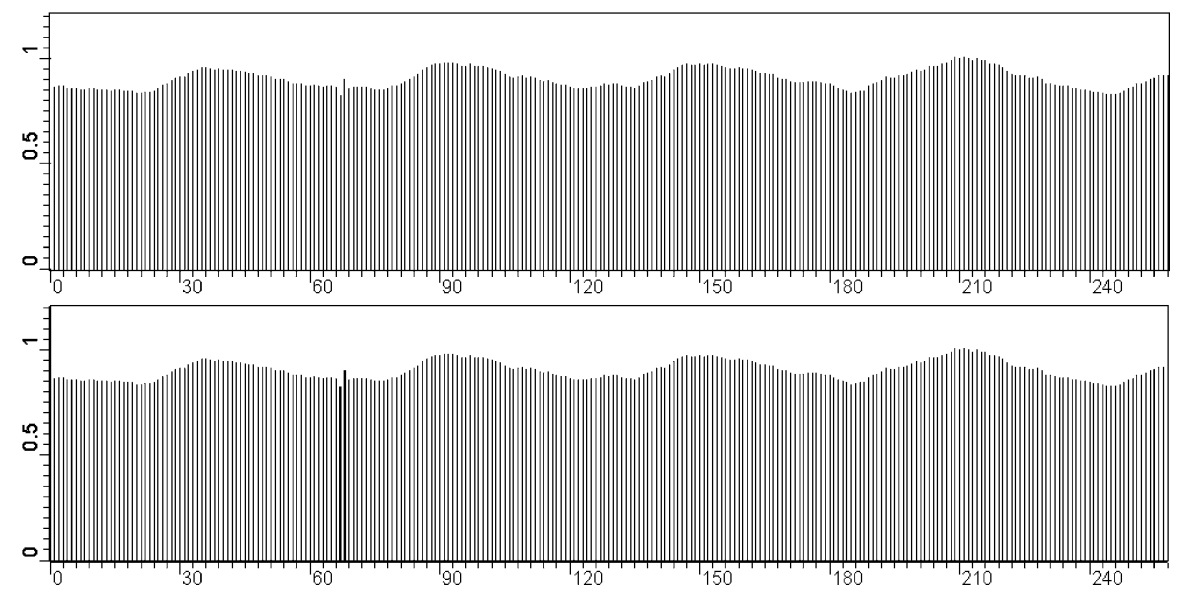

Fig. 7. The upper picture represents the sequence $y(i), i=1, \ldots, 258$ in which there is a premature beats. The lower picture shows that the recognition system has made a correct decision.

\section{Conclusions}

The theory and the constructive method presented provides an opportunity to recognize single short-time specific random elements that appear in the background of random sequences.

The probability that decisions about the existence of an isolated short-time specific random element in the background of a random sequence, while it doesn't exist in reality, will be made, is posed and controlled on the reliability level $\alpha$ of hypothesis verification.

There are no possibilities to estimate the probability of individual short-time specific elements missed without their statistical characteristics. However, this shortcoming can 
be eliminated. To this end, it is reasonable to invoke the theory and method for recognizing short-time random specific elements, described in this paper. They provide with a possibility to accumulate missing information by analyzing the properties of short-time specific random elements and use it in the estimation of probabilities of short-time specific random elements.

\section{References}

Atanasov, N., Ichtev, A. (2010). Closed-loop system identification with modifications of the instrumental variable method. Informatica, 21(2), 159-174.

Basseville, M., Benveniste, A. (Eds.) (1985). Detection of Abrupt Changes in Signals and Dynamical Systems. Springer, Berlin.

Basseville, M., Nikiforov, I.V. (1993). Detection of Abrupt Changes: Theory and Applications. Prentice-Hall, Englewood Cliffs.

Goss, F., Middeke, M., Mengden, T., Smetak, N. (2009). Praktische Telemedizin in Kardiology und Hypertensiologie. Georg Thieme Verlag KG.

Kassam, S.A. (1980). A bibliography on non-parametric detection. IEEE Transactions on Information Theory, IT-26, 5, 595-602.

Kligienè, N.,Telksnys, L. (1983). Methods of detecting instant of change of random process properties. Translated from Avtomatika i Telemechanika, 10, 5-56. Automation and Remote Control, 1984, 1241-1283.

Klersy, C., De Silvestri, A., Gabutti, G., Regoli, F., A.uricchio, A. (2009). A meta-analysis of remote monitoring of heart failure patients. Journal of the Americal Collerege of Cardiology, 54, 1683-1694.

Kruopis, J. (1977). Matematine statistika. Vilnius.

Pupeikis, R. (2010). On a time-varying parameter adaptive self-organizing system in the presence of large outliers in observations. Informatica, 21(1), 79-94.

Shaban, S.A. (1980). Change point problem and two-phase regression: a annotated bibliography. International Statistical Review, 48, 83-93.

Telksnys, L. (1986). The reliability resoliution of detecting the instants of change in the properties of random sequences. Detecting changes in random processes. In: L. Telksnys (Ed.), Optimization Software. Inc. Publications Division, New York, pp. 175-183.

Telksnys, L. (1987). Recognition of nonstationary random processes. In: Sinha, N.K., Telksnys, L. (Eds.), Stochastic Control Proceedings of the 2nd IFAC Symposium. IFAC Proceedings Series, Vol. 2, Pergamon Press, pp. 31-36.

Willsky, A.S. (1976). A survey of design methods for failure detection in dynamic systems. Automatika, 12, 601-11. 
L. Telksnys, professor, doctor habilitatis in informatics, doctor honoris causa of the Kaunas University of Technology, member of Lithuanian Academy of Sciences, head of Recognition Processes Department at the Vilnius University Institute of Mathematics and Informatics, Vilnius, Lithuania. He is the author of an original theory of detecting changes in random processes, investigator and developer of a computerized system for statistical analysis and recognition of random signals. His current research interests are in analysis and recognition of random processes, cardiovascular signals and speech processing and computer networking.

J. Kaukėnas, researcher of the Recognition Processes Department at the Vilnius University Institute of Mathematics and Informatics, Vilnius, Lithuania. He is an author of a mathematical methods and software systems for cardiovascular signals analysis. His current research interest are in cardiovascular signals recognition theory and software investigation.

\section{Trumpalaikių specifinių atsitiktiniụ elementụ atpažinimas atsitiktinèse sekose}

\section{Laimutis TELKSNYS, Jonas KAUKĖNAS}

Nagrinèjamos atsitiktinès sekos, kuriu fone atsitiktiniais laiko momentais gali pasirodyti trumpalaikiai atsitiktiniai specifiniai sekos elementai. Išdėstyta teorija ir konstruktyvūs metodai trumpalaikių atsitiktinių specifinių elementu, galinčių pasirodyti atsitiktinių sekų fone atpažinimui. Pateikiami eksperimentinių tyrimų rezultatai. Aptartos gautų rezultatų platesnio panaudojimo perspektyvos. 